\title{
Digital Marketing: Significance and Trending Strategies During COVID-19
}

\author{
Jyoti Gogia ${ }^{1 *}$, Sawan Nanda ${ }^{2}$ \\ ${ }^{I}$ Student, Department of Management Studies, Netaji Subhas University of Technology, New Delhi, India \\ ${ }^{2}$ Student, Department of MBA, IIM Indore, Indore, India \\ *Corresponding author: jyotigogia434@gmail.com
}

\begin{abstract}
Marketers are faced with new challenges and opportunities within this digital age. Digital marketing is the utilization of electronic media by the marketers to promote the products or services into the market. The main objective of digital marketing is attracting customers and allowing them to interact with the brand through digital media. The paper focuses on significance of digital marketing during COVID-19 and also discusses some trending digital marketing strategies.
\end{abstract}

Keywords: COVID-19, Digital marketing, Social media, Strategy.

\section{Introduction}

COVID-19 has considerably affected each part of our lives, and organizations - big and small - have been affected by this crisis. In such a situation, the main thing that has all the earmarks of being the beam of expectation is the help of technology. All ventures across sectors are attempting their level best to leverage digital solutions to sort their functions and pull through. After months of lockdown and social distancing because of COVID-19, consumers have been compelled to shop differently - reprioritizing what is essential and swapping the checkout line for online shopping, all the more so.

The situation we are confronting leaves no other option: to significantly improve e-commerce. Those companies that had digital platforms already started with an incredible bit of leeway. Others have been compelled to change, to adjust to online consumption and their products, to demand.

According to a recent survey of about 3700 consumers by UNCTAD (United Nations Conference on Trade and Development), on "COVID-19 and E-commerce", more than half of the survey's respondents now shop online more frequently and these changes will have lasting effects as the world's economy begins to recover.

Due to COVID-19, the Internet has become a vital part of people's lives, digital marketing has emerged to be an indispensable tool for companies. Companies are pivoting their tactics and budgets to creatively solve new problems such as (limited in-person experiences, technological knowledge gaps hindering productivity, and new work environments). In times like now, companies need to carefully redefine their marketing strategy and adopt a sensitive approach to communicate with its customers using digital solutions.

If the companies can see the benefits and opportunities that digital channels can offer, this will become part of their longterm marketing contingency plans.

\section{Aim}

- To analyse the impact of Covid-19 on digital marketing and find out its significance.

- To discuss trending digital marketing strategies during COVID-19.

\section{Methodology}

A qualitative analysis of secondary data was done to achieve research objectives. The data for this research paper has been collected using secondary data sources such as online blogs, websites, articles and various other secondary sources to study the impact and significance of digital marketing during COVID-19 in order to better understand the topic "Digital Marketing: Significance and trending strategies during COVID-19"

\section{Importance of Digital Marketing During COVID-19}

\section{A. Create brand recognition}

Simply put, Consumers want to buy brands which they recognize so social media plays a crucial role as it allows for easy and effective brand building. Besides, it gets your audience looking at your brand, even when they aren't thinking about a product or brand. Due to the lockdown, consumers spend $20 \%$ more time on Instagram, as per Neilson's report where they come across new products and services, which they never knew about.

\section{B. Lead Generation}

Collecting leads on social media helps find people interested in a company. More importantly, these leads will help to keep in touch with potential customers - whether it's to make a special offer or share news about a product. Some social media has features to track interest shown by consumers in the products and services too. Digital marketing plays a substantial role by helping the companies in generation of leads, which 
otherwise would have been a big challenge in times of pandemic.

\section{Enhanced audience engagement}

Digital marketing enables direct communication between the consumers and companies, which on the other hand, was not possible in case of traditional media.

Companies can keep their audiences engaged through various means, as many people have resorted to using social media as a means for entertainment due to COVID-19.

\section{Cost-effective}

Social-media marketing is conceivably the most costproficient piece of an advertising technique. Being financially savvy is such a favorable position since you can see a more prominent quantifiable profit and hold a greater spending plan for showcasing and operational expenses. In the covid-19 era, digital marketing is very helpful since it's much more affordable than using traditional marketing and helps to reach a much wider audience.

\section{Trending Digital Marketing Strategies}

\section{A. Optimize local and international SEO based on geographical diversifications}

COVID-19 being a global issue, economies have been impacted differently. To put a brand back in the market, domestic and international SEO has to be focused equally. It is important to diversify SEO on the basis of regions and has become an integral part of the 'new normal' digital marketing strategy. It might take a while for the outcomes to appear yet this is the clarion call for all advertisers out there to adjust to the evolving times.

\section{B. Concoct new payment methods to increase customer conversions}

The unavoidable lockdown limited individuals inside their homes and that has extraordinarily affected the business and income. On account of this, customer conversions diminished radically. Different payment plans can be offered. The assortment of payment plans that you offer can help lessen the budgetary weight of your clients and you can see a development in your profits immediately.

\section{Choose cheaper paid advertising}

Due to the long periods of lockdown, small brands can also afford paid advertising rather than just established brands as with increase in web traffic globally, slots for paid advertisements have increased and the costs have decreased. Hence, this is a golden chance for small brands to opt for paid advertising.

\section{Summary and Conclusion}

While it is given that the repercussions of COVID-19 pandemic will have long term implications, there's always the possibility of turning a tragedy into an opportunity.

Digital Marketers have the chance to redefine their business goals, get extra focused, keep an eye on the trends and strive to evolve continuously. it is likely that for many, using the internet more for shopping, gaming, keeping in touch and other activities will have become something of a habit. As the world goes increasingly digital, so will marketing. What digital marketers need to do is respond with updated strategies and buyer personas for a different, post-pandemic world.

\section{References}

[1] https://unctad.org/news/covid-19-has-changed-online-shopping-foreversurvey-shows

[2] https://www2.deloitte.com/si/en/pages/strategyoperations/articles/changing-consumer-digital-marketing-impact-Covid19.html

[3] https://zenmedia.com/how-covid-19-is-changing-digital-marketing/

[4] https://www.forbes.com/sites/bernardmarr/2020/03/20/why-companiesturn-to-digital-marketing-to-survive-covid-19/?sh=1cfa70452425

[5] https://digitalagencynetwork.com/why-will-the-covid-19-crisis-boostdigital-marketing-in-the-future/

[6] https://brandequity.economictimes.indiatimes.com/news/marketing/elev ate-your-digital-strategy-during-the-covid-19-crisis/76240832 